Poznań Studies in Contemporary Linguistics 52(4), 2016, pp. 583-604

(C) Faculty of English, Adam Mickiewicz University, Poznań, Poland

doi: 10.1515/psicl-2016-0023

\title{
EARLY LEXICAL COMPOSITION OF TURKISH-DUTCH BILINGUALS: NOUNS BEFORE VERBS OR VERBS BEFORE NOUNS
}

\author{
FATMA HÜLYA ÖZCAN \\ Anadolu University, Eskişehir \\ fozcan@anadolu.edu.tr
}

FEYZA ALTINKAMIŞ

STEVEN GILLIS

University of Ghent

University of Antwerp

\begin{abstract}
Nouns and verbs are considered as fundamental categories of lexical development, and there are contradicting views on the order of the acquisition. One view claims that nouns are acquired earlier than verbs and this primacy of nouns can be attributed to perceptualconceptual constraints from a linguistic point of view, on the other hand, nouns and verbs are the lexical units which categorically highlight language-general and languagespecific characteristics. These language-specific characteristics have motivated this research because of the different typological characteristics between Turkish and Dutch in terms of nouns and verbs. The aim of this study is two-fold: to investigate the Dutch and Turkish lexicon of Turkish-Dutch bilingual children with respect to noun-verb categories and to consider the role of gender. Our sample comprised 55 Turkish-Dutch bilingual children aged between 9 and 36 months. We found that age, language and gender are at play during early lexical development. Vocabulary develops after 12 months and nouns are prioritized over verbs both in comprehension and production.
\end{abstract}

KEYWORDS: noun-verb bias; Turkish-Dutch bilinguals; early lexicon.

\section{Introduction}

The present study is one part of a broader project addressing the languagegeneral and language-specific processes in Turkish-Dutch bilingual children's early lexical development. The aim of this study is two-fold: to investigate the nature of the early vocabulary composition in Turkish-Dutch bilingual children with respect to noun-verb categories and to consider the role of gender. In addi- 
tion, from the methodological aspect, this research aims to extend the use of the Communicative Development Inventory (CDI, hereafter), a valuable and valid tool for early period child language research, with a new bilingual pair; namely, Turkish-Dutch.

\section{Theoretical framework}

Discovering the shared milestones about monolingual children's early language development, researchers have changed their perspectives into bilingual populations as the number of children being raised in bilingual contexts continues to grow. One of the patterns investigated with bilingual populations, parallel to studies with monolingual populations, is the three waves of organization -from reference to predication, and then, to grammar- in children's early lexical acquisition. This lexical pattern found by Bates et al. (1994) in monolingual Englishspeaking children and in a cross-linguistic study with English and Italian children by Caselli et al. (1999) was also observed in Conboy and Thal's work with English-Spanish bilingual toddlers (2006) and with Cypriot Greek and Standard Modern Greek bilectal children (Taxitari et al. 2016). Another lexical trajectory in monolingual children's early language development is the (so-called) universality of noun-first predisposition. Among a wide range of word classes, nouns and verbs have received more attention in understanding children's early lexical development since they are the only word classes to defend universal status (Trask 1999).

The results of the studies conducted with monolingual populations have been so challenging that addressing the same research perspective with bilingual populations has been inevitable. What makes noun dominance over verbs in children's early word learning so interesting is the challenging interaction between cognitive versus linguistic factors, which has taken its roots from mainly Gentner's perspectives $(1981,1982)$ and the counter arguments to her claims: a) perceptual-conceptual constraints underlying noun primacy in children's early lexicon (Gentner 1981, 1982) versus b) language-specific input via childdirected speech as a determination of the nature of children's early lexicon (Choi and Gopnik 1995; Tardif 1996). According to Gentner's universal noun advantage view, children are equipped with specific, innate cognitive and perceptual constraints and the distinction between nouns and verbs across languages derives from the conceptual difference between them. As nouns are heavily associated with concrete objects and entities which are easy to label and to establish a clear referent, they are conceptually easier to acquire and are also 
more fundamental than verbs. This makes nouns perceptually more transparent and straightforward to acquire than verbs. This simple conceptualization of nouns does not differ from one language to another. Therefore, Gentner concluded that noun-primacy in children's early lexicon is a language-general characteristic. On the other hand, verbs and other predicates represent relational terms and these terms vary from one language to another. Besides, the relations that verbs and predicates represent are more various than those of nouns even in a specific language such as path or manner of an action (Gentner and Boroditsky 2009). Therefore, in children's language acquisition, setting the constraints related to verbs and predicates require more time and exposure and, therefore, is a complex process for children (Gentner 1982).

Gentner's claim about the universality of the noun-biased pattern of children's early lexical development has been challenged by data from a great number of researchers. These researchers highlighted the importance of languagespecific characteristics through child-directed speech (Choi and Gopnik 1993, 1995; Tardif 1993, 1996; Tardif et al. 1997). Tardif et al. (1997) focused on typologically different languages such as Italian, Mandarin and English and concluded that cognitive-perceptual constraints are not determinant on children's language but language-specific characteristics of the input language make a difference to children's language. Related research findings have mainly accumulated on languages with different characteristics such as Mandarin, Korean, and Turkish on the one hand, and English, French, German and Dutch on the other, since language characteristics of these languages represent good examples to tackle. Leading researchers in this domain such as Choi and Gopnik (1995), Tardif (1996), Tardif et al. (1997), Ogura et al. (2006) and Gentner (1982) divided factors to consider into three: word order, morphological transparency and patterns of parents' language teaching. Among these categories, word order and morphological transparency have been widely noted in explaining the differences between verb and noun friendly languages. In verb friendly languages, verbs are richly inflected, and in some of them such as Turkish and Japanese, a verb can stand for a complete sentence with appropriate inflections. The subject is not obligatory. In noun friendly languages, however, such as French and Dutch, nouns are not elided and the subject is obligatory. Since noun phrases can be dropped in verb friendly languages, verbs are used in salient positions in the utterances when compared to noun friendly languages. When it comes to patterns of parents' language teaching, in other words, parents' language practice type with children, in general, a number of studies have found that mothers speaking verb friendly languages use more verb-oriented utterances than nounoriented utterances when talking to their children (Altınkamıs et al. 2014; Choi 
and Gopnik 1995). Various different languages have been considered in followup and recent studies. For example, Gentner and Boroditsky (2009) focused on Navajo, a less studied language with respect to language acquisition, exhibiting language properties similar to verb friendly languages as given above. The findings from Navajo supported noun dominance over verbs in early language acquisition. All studies mentioned so far were conducted with monolingual children. A different target group, bilectal children with specific language impairment was considered in studies by Kambanaros et al. (2014) and Taxitari et al. (2016). Kambanaros and her team extended the studies addressing noun and verb acquisition related research to atypical populations from a deeper psycholinguistic perspective in Cypriot Greek bilectal children. Their findings contribute to the related findings from two aspects. First, the discussion based on the noun superiority over verbs was supported with data from a new language, Greek, a highly inflected language with a complicated morphological system but similar degree of complexity on nouns and verbs. Second, the participants were of unique with their characteristics: children speaking two different dialects of the same language and children with specific language impairment. (Kambaranos 2013; Kambanaros 2016; Kambanaros et al. 2014). With their special group, they observed significant impairment on action naming when compared to object naming (Kambanaros et al. 2014). They further opened a new discussion related to similarities between bilingual and bilectal children (Taxitari et al. 2016).

Lucas and Bernardo (2008) with Filipino-English and Xuan and Dollaghan (2012) with Mandarin-English bilinguals have concentrated on the interaction of two languages. Referring to the background given above, Mandarin, Filipino and English have been significant languages regarding noun-verb acquisition pattern as the structural differences are striking. According to Xuan and Dollaghan (2012: 5), Mandarin and English "are believed to fall near the extreme ends of the noun bias continuum". In their studies with 50 Mandarin-English bilingual children and 60 Filipino-English bilingual children, they observed the noun bias for both languages and stated that noun dominance was significantly higher in the children's English lexicon, highlighting the interaction between both language-general and language-specific mechanisms.

We propose that this is an important research aspect to investigate further in bilingual populations since a bilingual child is exposed to two different language systems Similar to English and Mandarin as in Xuan and Dollaghan (2012) and to Filipino and English as in Lucas and Bernardo (2008), this aspect raises more attention if two structurally different languages are taken into consideration. Attempts to reach general consensus should consider other language 
pairs in bilingual populations. For this reason, our study focuses on Turkish and Dutch. According to studies with findings on noun superiority over verbs, Dutch has been accepted as a noun-friendly language (Gillis and Verlinden 1988), whereas Turkish is seen as a verb-friendly one (Türkay 2005; Küntay and Slobin 2001; Aksu-Koç and Slobin 1985; Ketrez and Aksu-Koç 2003). The structural differences between Dutch and Turkish indicate a challenging case to explore further with Turkish-Dutch bilinguals. For example, the subject is obligatory in Dutch but not obligatory in Turkish. Dutch verbs and nouns are nearly equally inflected but Turkish verbs are highly more inflected than Turkish nouns. The canonical word order in Turkish is SOV but in Dutch, it is SVO making Turkish verbs more salient than Dutch verbs. Turkish is also a pro-drop language whereas Dutch is not.

We predict that if the noun-before-verb pattern is a language-general trajectory and a universal pattern as proposed by Gentner (1982), we will observe noun dominance over verbs in the children's early Dutch and Turkish lexicon. However, if we observe verb superiority over nouns or equal use of nouns and verbs in the children's Turkish lexicon and noun superiority over verbs in the children's Dutch lexicon, this can shed light on the interaction of languagespecific processes.

\section{Method}

\subsection{Procedure}

The adaptation of the well-known and widely used parental report, namely, the Communicative Development Inventory, into several languages has enabled us to work with the bilingual populations as well through a valid and reliable measure in both languages considered. Following the studies on early lexicon using CDI with monolingual populations and studies comparing different monolingual populations (Kern 2004; Jackson-Maldonado et al. 1993), researchers then gave attention to bilingual samples (Marchman and Martinez-Sussman 2000; Conboy and Thal 2006) and bilectal samples (Taxitari et al. 2016). The adaptation of the CDI into Turkish was recently completed (Aksu-Koç et al. 2009), allowing us to embark on further research with a large group of Turkish monolingual or bilingual children (T-CDI). The CDI was adapted into Dutch by Zink and Lejaegere in 2002 (Zink and Lejaegere 2002) (N-CDI). The T-CDI and the N-CDI were administered separately as we aimed to see the nature of the early acquired words in each language, independent of each other. In order 
to receive the best output from the inventories, the families were requested to fill in the T-CDI and the N-CDI, depending on the language in which they felt competent. In some instances, the mother filled in both forms whereas in other cases, the father filled in the N-CDI and the mother the T-CDI or vice versa. In a limited number of cases, the kindergarten teacher of the child filled in the $\mathrm{N}$ CDI. The T-CDI and the N-CDI has two forms: one designed for children aged between $0 ; 8$ and 1;04 (infant form-CDI-I) and the other for 1;05 to 3;00 (toddler form-CDI-II) (see Appendix 1 and 2 for detailed information about the lexical categories in the T-CDI and N-CDI).

\subsection{Subjects}

The sample consisted of 55 Turkish-Dutch bilingual children aged between 8 and 36 months whose parents completed the T-CDI and the N-CDI. 21 children's parents completed the CDI-I and 34 children's parents completed the CDI-II. The data were collected in Flanders, from a Dutch-speaking community mainly resident in the cities of Ghent and Antwerp in Belgium. Table 1 gives some descriptive information about the participants.

Table 1. Descriptive characteristics of the participants.

\begin{tabular}{llcc}
\hline \multirow{2}{*}{ Gender } & & CDI-I & CDI-II \\
& Boys & 10 & 18 \\
& Girls & 11 & 16 \\
\hline \multirow{2}{*}{ Birth order } & First-born & 7 & 12 \\
& Later-born & 14 & 22 \\
\hline \multirow{2}{*}{ Home language } & Dutch dominant-Turkish weak & 5 & 12 \\
& Turkish dominant-Dutch weak & 16 & 22 \\
\hline
\end{tabular}

The sample was further divided into 5 subgroups according to the ages.
(1) 8 months-11 months
11 subjects
$(\mathrm{CDI}-\mathrm{I})$
(2) 12 months -16 months
10 subjects
$(\mathrm{CDI}-\mathrm{I})$
(3) 17 months -23 months
12 subjects
(CDI-II)
(4) 24 months -30 months
7 subjects
(CDI-II)
(5) 31 months -36 months
15 subjects
(CDI-II) 


\subsection{Vocabulary measures}

To be consistent with related studies in the field (Xuan and Dollaghan 2012), we followed a conservative definition of noun and verb categorisation. The common nouns category included "animals", "vehicles", "toys", "food and drink", "clothing", "body parts", "small household items, and "furniture" and the verb category included only "action words".

\subsection{Analysis}

First of all, we analyzed the frequency of verbs and nouns. Mean and median values of nouns and verbs were calculated for each age group. Calculating the median (the middle score) for each data group is necessary when the data shows a wide range of scores since the median value is affected neither by extremely high nor by extremely low scores (Field 2009: 21). The composition of nouns were displayed through raw scores and percentages. In order to reveal any significant differences among the occurrences of nouns and verbs in each age group and among the genders, we used paired samples t-test, independent samples t-test and ANOVA with repeated measures when the data displays normal distribution and their nonparametric correspondents such as Wilcoxon Signed Rank test, Mann-Whitney U test, Kruskal Wallis test, and Friedman's rank test when the data displays binomial distribution. Statistical analysis was conducted through SPSS 18.

\section{Results}

\subsection{Findings on CDI-I}

\subsubsection{Nouns before verbs or verbs before nouns?}

CDI-I focuses on early vocabulary development between 8 and 16 months. In this section, we will have a close look at both the comprehension and the production of Turkish and Dutch vocabulary between 8 and 16 months. In CDI studies, the tendency is to calculate a comprehension score for each child by summing the number of words the child is able to understand with the number of words the child is able to understand and produce. The comprehension scores, therefore, includes the comprehension of words that were not produced 
and the comprehension of words that were also produced (Kern 2007: 234; De Houwer et al. 2014: 1200). Following this established tradition, the comprehension scores in this study includes the total number of words comprehended with and without production.

Table 2. Comprehension data between 08-11 and 12-16 months in Turkish and Dutch (T-CDI-I and N-CDI-I).

\begin{tabular}{|c|c|c|c|c|}
\hline \multirow{4}{*}{ Total } & \multicolumn{4}{|c|}{ Turkish } \\
\hline & \multicolumn{2}{|c|}{ 08-11 months } & \multicolumn{2}{|c|}{$12-16$ months } \\
\hline & \multicolumn{2}{|c|}{215} & \multicolumn{2}{|c|}{480} \\
\hline & Nouns & Verbs & Nouns & Verbs \\
\hline $\mathrm{N}$ & 149 & 66 & 289 & 191 \\
\hline$\%$ & $69 \%$ & $31 \%$ & $60 \%$ & $40 \%$ \\
\hline Mean & 13.2 & 6.3 & 26.5 & 17.1 \\
\hline SD & 17.1 & 11.9 & 25.4 & 17.2 \\
\hline Median & 5 & 2 & 17 & 13 \\
\hline \multirow[t]{3}{*}{ Min-max } & $0-53$ & $0-39$ & $2-82$ & $0-47$ \\
\hline & \multicolumn{4}{|c|}{ Dutch } \\
\hline & $08-1$ & nths & $12-1$ & nths \\
\hline \multirow[t]{2}{*}{ Total } & \multicolumn{2}{|c|}{115} & \multicolumn{2}{|c|}{88} \\
\hline & Nouns & Verbs & Nouns & Verbs \\
\hline $\mathrm{N}$ & 80 & 35 & 70 & 18 \\
\hline$\%$ & $70 \%$ & $30 \%$ & $80 \%$ & $20 \%$ \\
\hline Mean & 7.4 & 3.5 & 2.7 & 0.8 \\
\hline SD & 9.9 & 5.4 & 4.7 & 1.2 \\
\hline Median & 3 & 0.5 & 0.5 & 0 \\
\hline Min-max & $0-31$ & $0-16$ & $0-15$ & $0-3$ \\
\hline
\end{tabular}

In CDI-I, children between $8-11$ and $12-16$ months have larger vocabulary in Turkish than they have in Dutch (695 words in Turkish and 203 words in Dutch). The developmental tendency draws a different profile in two languages so we get a closer look at the languages separately. 
In Turkish, the total number of words increases with age. Children between 8-11 months can understand 215 words and this number increases up to 480 between 12-16 months. This increase is statistically significant $(\mathrm{Z}=-2.18 ; \mathrm{df}=$ $19 ; p=0.02)$. In Dutch, on the other hand, the total number of words decreases between 12-16 months (115 and 88 words respectively). This may be the result of the dominant home language being Turkish in the 12-16 month group. Although Dutch vocabulary decreases with age, this is not statistically significant $(\mathrm{Z}=-0.58 ; \mathrm{df}=19 ; \mathrm{p}=0.55)$.

When we compare the verbs and nouns in both languages, we see that children comprehend more nouns than verbs both in Turkish and in Dutch. The tendency is the same within the 12-16-month-group as well. Mixed design ANOVA analysis revealed a statistically significant linear within-group effect between Turkish and Dutch, indicating that language makes a significant difference in terms of verbs and nouns $(F=5.26 ; p=0.03)$. Age does not impose a difference on either Turkish or Dutch $(F=2.7 ; p=0.116)$. This may be explained by the fact that CDI-I is applied by the end of 16 months just before the vocabulary spurt takes place. Bates et al. (1994) suggest that a steady linear increase in vocabulary takes place between 16 and 30 months. Since language makes the significant main effect on nouns and verbs at this age group, the order of acquisition of nouns and verbs across languages is shown in regard with Turkish and Dutch (Table 3).

Table 3. Mean ranks of nouns and verbs in Turkish and Dutch.

\begin{tabular}{ll}
\hline & Mean rank \\
\hline Comprehension of Turkish nouns & 3.58 \\
Comprehension of Turkish verbs & 2.58 \\
Comprehension of Dutch nouns & 2.25 \\
Comprehension of Dutch verbs & 1.61 \\
\hline
\end{tabular}

As shown, the order of acquisition is revealed as Turkish nouns $>$ Turkish verbs $>$ Dutch nouns $>$ Dutch verbs. The difference across the categories is statistically significant $\left(\mathrm{X}^{2}=27.1 ; \mathrm{df}=3 ; \mathrm{p}<.001\right)$ except for the verb categories between languages; that is to say, there is no statistically significant difference between verbs in Turkish and nouns in Dutch $(Z=-1.83 ; p=0.06)$. 
We then looked at the production of nouns and verbs in CDI-I. The number of the total words produced is relatively less than the number of the total words comprehended. Production data is summarized as below.

Table 4. Production data between 8-11 and 12-16 months in Turkish and Dutch (T-CDI-I and N-CDI-I).

\begin{tabular}{|c|c|c|c|c|}
\hline \multirow{4}{*}{ Total } & \multicolumn{4}{|c|}{ Turkish } \\
\hline & \multicolumn{2}{|c|}{ 08-11 months } & \multicolumn{2}{|c|}{$12-16$ months } \\
\hline & \multicolumn{2}{|c|}{3} & \multicolumn{2}{|c|}{44} \\
\hline & Nouns & Verbs & Nouns & Verbs \\
\hline $\mathrm{N}$ & 3 & 0 & 24 & 20 \\
\hline$\%$ & $100 \%$ & - & $55 \%$ & $45 \%$ \\
\hline Mean & 0.3 & - & 2.4 & 2 \\
\hline SD & 0.9 & - & 3.3 & 3.8 \\
\hline Median & 0 & - & 1 & 0.5 \\
\hline \multirow[t]{3}{*}{ Min-max } & $0-3$ & - & $0-10$ & $0-12$ \\
\hline & \multicolumn{4}{|c|}{ Dutch } \\
\hline & $08-1$ & nths & $12-1$ & nths \\
\hline \multirow[t]{2}{*}{ Total } & \multicolumn{2}{|c|}{6} & \multicolumn{2}{|c|}{53} \\
\hline & Nouns & Verbs & Nouns & Verbs \\
\hline $\mathrm{N}$ & 6 & 0 & 43 & 10 \\
\hline$\%$ & $100 \%$ & - & $81 \%$ & $19 \%$ \\
\hline Mean & 0.6 & - & 4.3 & 2 \\
\hline SD & 1.8 & - & 13.5 & 3.8 \\
\hline Median & 0 & - & 0 & 0.5 \\
\hline Min-max & $0-6$ & - & $0-43$ & $0-12$ \\
\hline
\end{tabular}

Production is limited to a few words between 8-11 months in both languages. Production data conform to the results of the studies by Bates et al. (1994), Kern (2007) and De Houwer (2014), which indicate that lexical production is limited before 12 months. After 12 months, lexical production increases in our data as well. Between 12-16 months, there are 44 words produced in Turkish and 53 words in Dutch. The difference between the languages is not statistically signif- 
icant $(Z=-1.183 ; p=297)$. This number, in fact, is the number of words produced by only one child in the sample. Individual reasons underlying this difference will be further delineated in the discussion section. Nouns are more frequently produced than verbs in both languages but the ratio of nouns and verbs display a different profile in Turkish and Dutch. In Turkish, 55\% of these words are nouns and $45 \%$ of them are verbs. On the other hand, $81 \%$ of Dutch vocabulary consists of nouns and $19 \%$ consists of verbs. There is no statistically significant interaction between language and the lexicon type. That is, the lexicon type is not significantly affected by the language produced $(\mathrm{F}=0.669 ; \mathrm{p}=$ $0.434)$.

Table 5. Mean ranks of nouns and verbs produced in Turkish and Dutch.

\begin{tabular}{ll}
\hline & Mean rank \\
\hline Production of Turkish nouns & 2.95 \\
Production of Turkish verbs & 2.65 \\
Production of Dutch nouns & 2.25 \\
Production of Dutch verbs & 2.15 \\
\hline
\end{tabular}

The order of acquisition in production is Turkish nouns $>$ Turkish verbs $>$ Dutch nouns $>$ Dutch verbs. The mean ranks reveal that Turkish is the dominant language in production and Dutch nouns and verbs follow Turkish nouns and verbs. There is no statistically significant difference among the language groups $\left(\mathrm{X}^{2}=1.2 ; \mathrm{df}=3 ; \mathrm{p}=.735\right)$.

\subsubsection{Gender difference in CDI-I}

Total scores of nouns and verbs in both languages across genders are given below in Table 6.

We see gender effects both on comprehension and production. In Turkish, boys comprehend more nouns and verbs than girls do. However, girls produce more Turkish nouns than boys. Boys, again, are more productive in terms of verbs than girls. In Dutch, girls outperform boys in all aspects. Girls comprehend more nouns and more verbs than boys in Dutch. In terms of production, we see that girls are more productive on nouns and verbs. Girls' productive vo- 
Table 6. Distribution of nouns and verbs in Turkish and Dutch across genders (T-CDI-I and N-CDI-I).

\begin{tabular}{|c|c|c|c|c|}
\hline \multicolumn{5}{|c|}{ Turkish } \\
\hline & \multicolumn{2}{|c|}{ Noun } & \multicolumn{2}{|c|}{ Verb } \\
\hline & Comprehension & Production & Comprehension & Production \\
\hline Girls & 205 & 16 & 121 & 1 \\
\hline Boys & 233 & 11 & 142 & 19 \\
\hline \multicolumn{5}{|c|}{ Dutch } \\
\hline & \multicolumn{2}{|c|}{ Noun } & \multicolumn{2}{|c|}{ Verb } \\
\hline & Comprehension & Production & Comprehension & Production \\
\hline Girls & 115 & 49 & 44 & 10 \\
\hline Boys & 35 & 0 & 9 & 0 \\
\hline
\end{tabular}

cabulary in Dutch supports the idea stating that girls are more articulate than boys. The productive vocabulary in Turkish, on the other hand, indicates that boys have more verbs in their productive vocabulary than girls have. These figures indicate that they are not at a stage to accept two labels for a single entity; however, it would be immature to bring up a plausible explanation to this issue without further analysis, yet.

\subsection{Findings on CDI-II}

\subsubsection{Nouns before verbs or verbs before nouns?}

CDI-II focuses on later vocabulary development between 17 and 36 months. In this section, we will have a close look at the production of the Turkish and Dutch vocabulary between 17 and 36 months. Since the age span is wide and the vocabulary spurt especially takes place between 16 and 30 months (Bates et al. 1994; Kern 2007), we have divided this developmental period into 3 age spans. The analysis has been conducted in relation to these 3 age spans.

The profile of CDI-II is as follows: The number of words produced increases with increasing age both in Turkish and in Dutch. When we compare the number of words between the languages, we can observe that Dutch vocabulary is larger than Turkish vocabulary until 30 months. After 30 months, children 
Table 7. Production data between 17-36 months in Turkish and Dutch (T-CDI-II and N-CDI-II).

\begin{tabular}{|c|c|c|c|c|c|c|}
\hline \multirow{4}{*}{ Total } & \multicolumn{5}{|c|}{ Turkish } & \\
\hline & \multicolumn{2}{|c|}{ 17-23 months } & \multicolumn{2}{|c|}{ 24-30 months } & \multicolumn{2}{|c|}{$31-36$ months } \\
\hline & \multicolumn{2}{|c|}{356} & \multicolumn{2}{|c|}{671} & \multicolumn{2}{|c|}{3501} \\
\hline & Nouns & Verbs & Nouns & Verbs & Nouns & Verbs \\
\hline $\mathrm{N}$ & 226 & 130 & 510 & 161 & 2262 & 1239 \\
\hline$\%$ & $63 \%$ & $37 \%$ & $76 \%$ & $24 \%$ & $65 \%$ & $35 \%$ \\
\hline Mean & 7.0 & 3.2 & 72.8 & 23 & 150 & 90.7 \\
\hline $\mathrm{SD}$ & 7.8 & 4.9 & 53.3 & 28.5 & 66.8 & 38.8 \\
\hline Median & 7 & 2 & 78 & 11 & 166 & 93 \\
\hline \multirow[t]{3}{*}{ Min-max } & $0-21$ & $0-14$ & $2-168$ & $0-75$ & $72-245$ & $32-133$ \\
\hline & \multicolumn{6}{|c|}{ Dutch } \\
\hline & $17-2$ & onths & $24-3$ & onths & $31-3$ & lonths \\
\hline \multirow[t]{2}{*}{ Total } & \multicolumn{2}{|c|}{499} & \multicolumn{2}{|c|}{1020} & \multicolumn{2}{|c|}{1756} \\
\hline & Nouns & Verbs & Nouns & Verbs & Nouns & Verbs \\
\hline $\mathrm{N}$ & 427 & 72 & 826 & 194 & 1433 & 323 \\
\hline$\%$ & $86 \%$ & $14 \%$ & $81 \%$ & $19 \%$ & $82 \%$ & $18 \%$ \\
\hline Mean & 32 & 6.7 & 118 & 27.7 & 117 & 33.5 \\
\hline SD & 71.7 & 16.8 & 83.2 & 26.7 & 105.4 & 37.1 \\
\hline Median & 3 & 0 & 119 & 23 & 106 & 17 \\
\hline Min-max & $0-194$ & $0-45$ & $1-224$ & $0-64$ & $0-279$ & $0-80$ \\
\hline
\end{tabular}

produce more Turkish words than Dutch. The statistical analysis indicates a significant difference among the age groups in terms of the Turkish and Dutch vocabulary produced $(\mathrm{F}=27.4 ; \mathrm{df}=33 ; \mathrm{p}=0.0001)$. When we compare the age groups, we see that a statistically significant increase in the number of Turkish words produced takes place between the 24-30-month-span and 30-36-month $\operatorname{span}(\mathrm{p}=0.01)$.

Verbs follow nouns in both languages in all age spans. Verbs, as well as nouns, increase with increasing age in both languages except for the 31-36month-period.The number of Dutch verbs decreases at this age span. There is a statistically significant difference between nouns and verbs in both languages $\left(\mathrm{X}^{2}=42.8 ; \mathrm{df}=3 ; \mathrm{p}=0.0001\right)$. In CDI-II, like CDI-I, Turkish is the dominant 
language and nouns are the dominant word categories in both languages as confirmed by the ordered rank of the categories (Table 8).

Table 8. Mean ranks of nouns and verbs in Turkish and Dutch in production.

\begin{tabular}{ll}
\hline & Mean rank \\
\hline Production of Turkish nouns & 3.51 \\
Production of Turkish verbs & 2.50 \\
Production of Dutch nouns & 2.43 \\
Production of Dutch verbs & 1.56 \\
\hline
\end{tabular}

The production order of word categories across languages is as follows; Turkish nouns $>$ Turkish verbs $>$ Dutch nouns $>$ Dutch verbs.

\subsubsection{Gender difference in CDI-II}

Total scores of nouns and verbs in both languages across genders are given below in Table 9.

Table 9. Distribution of nouns and verbs in Turkish and Dutch across genders.

\begin{tabular}{|c|c|c|c|c|c|}
\hline & & \multicolumn{4}{|c|}{ Turkish } \\
\hline & \multirow[t]{2}{*}{ Total } & \multicolumn{2}{|c|}{ Nouns } & \multicolumn{2}{|c|}{ Verbs } \\
\hline & & $\mathrm{N}$ & $\%$ & $\mathrm{~N}$ & $\%$ \\
\hline Girls & 3013 & 1942 & $64 \%$ & 1071 & $36 \%$ \\
\hline \multirow[t]{4}{*}{ Boys } & 1518 & 1056 & $70 \%$ & 459 & $30 \%$ \\
\hline & & \multicolumn{4}{|c|}{ Dutch } \\
\hline & Total & \multicolumn{2}{|c|}{ Nouns } & \multicolumn{2}{|c|}{ Verbs } \\
\hline & & $\mathrm{N}$ & $\%$ & $\mathrm{~N}$ & $\%$ \\
\hline Girls & 1590 & 1292 & $81 \%$ & 298 & $19 \%$ \\
\hline Boys & 1685 & 1394 & $83 \%$ & 291 & $17 \%$ \\
\hline
\end{tabular}


The general acquisition profile we have analysed so far is also observed in CDIII as well. The raw scores and proportion of nouns and verbs signal different tendencies between genders and between languages. In total, more words are produced in Turkish than in Dutch. Girls produce more words than boys in both languages and this difference between genders is statistically significant $(\mathrm{Z}=$ $-2.657 ; \mathrm{p}=0.007$ ). The mean rank for girls is 22.3 while it is 13.2 for boys indicating that girls produce a higher number of Turkish words than boys. A different picture is displayed in Dutch. Boys produce more Dutch words than girls do. However, this difference is not statistically significant $(Z=-0.207 ; p=$ 0.845 ). The mean ranks for boys is 17.8 and for girls is 17.1 indicating that boys' productions do not create a significant difference. Noun/verb bias draws the same profile indicating that boys and girls produce more nouns than verbs in both in Turkish and in Dutch.

Analysis and the interpretation of the findings reveal the interaction of age, language and gender in lexical development. Not only production but comprehension of lexical items is limited until 12 months and show a steady increase by age; that is, vocabulary grows as the children grow. Age also has an effect on noun categories produced in both languages.

\section{Discussion}

The present study provides a comprehensive picture of Turkish-Dutch bilingual children's early lexicon in terms of noun and verb production, considering gender difference. With 55 Turkish-Dutch bilingual children, this is the first study contributing to the related field by use of CDI with a new bilingual pair.

The accumulation of studies on the universality of noun bias in children's early lexicon has mainly come from cross-linguistic monolingual studies. To exemplify, Bornstein et al. (2004) made a cross-linguistic analysis of vocabulary in young children acquiring Spanish, Dutch, French, Hebrew, Italian, Korean and American English and mentioned the noun primacy over verbs in all these languages. That is, noun primacy over verbs is observed in Dutch-speaking children's lexical growth. Gentner's provoking results also come from a rich cross-linguistic sample including 6 languages: English, German, Turkish, Japanese, Kaluli and Mandarin. Gentner's two strictly interwoven hypotheses, the natural partitions hypothesis and the relational relativity hypothesis, and follow up studies mentioned above in the field may have resulted in the idea that the languages should be put into a scale with two extreme points as languages supporting noun bias or not. However, in time, as the findings emerged from di- 
verse languages, researchers shifted their bi-polar perspective into a continuum. There seems to be widespread agreement that noun-bias is not a dual process with extreme ends. Instead, it is a spectrum on which languages can stand at different points, in line with classificatory typology and language-specific characteristics. For example, Kauschke and Hofmeister's (2002) perspective is interesting. In their study with German monolingual children, they claimed that, in particular languages, it is possible to see a weaker or stronger version of the noun-bias hypothesis.

The bilingual children in the present study show an interaction of languagegeneral and language-specific processes. We conclude that general cognitive processes play a role in early lexicon acquisition. The Turkish-Dutch bilingual children's early receptive lexicon both in Turkish and Dutch is made up of nouns as observed in the T-CDI-I and in the N-CDI-I. However, verbs do not behave exactly the same way in the Dutch and Turkish lexicon. The difference between nouns and verbs is more significant in Dutch than it is in Turkish. This finding is compatible with the findings of French and Turkish monolingual children (Kern and Türkay 2006). Kern and Türkay (2006) also observed noun dominance over verbs but the difference between nouns and verbs was stronger in French than it was Turkish.

As for the toddler form (between 17-36 months), noun superiority over verbs is reported both in the Turkish and Dutch lexicon, again with a more remarkable difference in Dutch than in Turkish in terms of noun dominance over verbs. When the mean ranks of noun and verbs in both groups are considered, we always observe that nouns are acquired earlier than verbs in both languages, indicating the early noun advantage in both languages.

The results of the present study support the findings reported in the related literature in the way that early lexical patterns of bilingual children are similar to that of monolingual children. The noun-before-verb pattern observed in the Turkish-Dutch bilingual children's early language growth can be attributed to Gentner's general cognitive development principles. We can conclude that our findings are consistent with Gentner's natural partitions and relational relativity hypotheses but the pattern observed related to proportion of verbs over nouns in the children's Dutch and Turkish lexicon highlight the presence of languagespecific characteristics. Our results can be evaluated as convergent evidence to Xuan and Dollaghan's (2012) study with Mandarin-English bilingual children and Lucas and Bernardo's (2008) study with Filipino-English bilingual children.

Home language context is another important factor to consider in bilingual samples. Yet, in our study, home language has not been considered as an independent variable as we did not concentrate on the causal interaction between 
child-directed speech and children's productions. We only aimed to see the overall composition of the Turkish-Dutch bilingual children's early lexicon regarding their noun and verb uses. Even so, we categorized the families as Dutch-dominant/Turkish-weak families, in which one of the parents is Dutchspeaking and the other Turkish-speaking, considering the fact that they live in a Dutch- speaking community. We categorized the families as Turkishdominant/Dutch-weak families in which both parents are Turkish. As the age range of the children was between 8-36 months, very few had started to attend kindergarten or childcare centres. Most of them were cared for by their parents or grandparents at home. As this study is only one part of a broader on-going project, other variables will be taken into account when making different analysis with a different focus. We do not ignore that the quality and the quantity of the input especially in bilingual settings are extremely important as they provide required language exposure to bilingual children. Sometimes, in majority language contexts, minority language use provided by one of the parents at home can be the only source for children to expose that language. Therefore, future research should concentrate on the effects of child-directed speech in bilingual contexts on children's early language development.

As for the gender variable, in CDI-I, we observe that girls are more productive in their Dutch lexicon than boys but boys are more productive than girls in their Turkish lexicon. We also highlight more frequent use of verbs in Turkish by boys than girls and more frequent use of verbs in Dutch by girls than boys. The picture looks slightly different in CDI-II across genders. The girls are more productive than boys in their Turkish lexicon. The noun dominance over verbs is also seen in the girls' Turkish lexicon. No significant dominance of nouns over verbs is observed in the girls' Dutch lexicon over boys.

\section{Conclusion}

By considering a different sample with same research focus, this study concentrated on the acquisition pattern of two important grammatical word categories of early language development - nouns and verbs - at the surface level, and at the deep level, on the interaction of linguistic and cognitive processes. The developmental patterns in parental report data of the Turkish-Dutch bilingual children in this study resemble those of monolingual children with respect to a noun-before-verb pattern. In an overall manner, bilingual children following language general trajectories at first acquire the patterns of each language in a language-specific way. The use of a bilingual sample permitted us to better see 
this interaction in a new bilingual pair; Turkish and Dutch. In addition, the results of this study can be regarded as supporting data to Gentner and Boroditsky's (2009) rapprochement perspective in their argument about the interaction of conceptual and linguistic factors in their paper. They claim that nouns representing concrete entities are acquired earlier, providing referential mapping between language and the world. Early acquisition of nouns shows the way to children to go further with their language experience, especially for verbs and relational meanings. To generalize language-general and language-specific profiles of early bilingualism, the field is in need of more research and further analysis with different language pairs, with similar or different language characteristics.

\section{Acknowledgements}

This research has been funded by TUBITAK (Turkish Science Foundation) and FWO within the framework of the international collaboration project between Tubitak (Turkey) and FWO (Flanders/Belgium).

Special thanks to: Prof. Ayhan Aksu-Koç for providing Turkish CDI-I and CDI-II; Prof. Steven Gillis for providing Dutch CDI-I and CDI-II; Aysu Mutlutürk for providing help on how to use CDIs.

\section{REFERENCES}

Aksu-Koç, A., A. Küntay, F. Acarlar, İ. Maviş, H. Sofu, S. Topbaş and F. Turan. 2009. The assessment and evaluation of early lexical and grammatical development in Turkish: The Turkish Communicative Development Inventories, TIGE-I and TIGEII. (Final report of Project no: 107K058, submitted to Turkish Scientific and Technological Research Foundation.)

Aksu-Koç, A. and D.I. Slobin. 1985. “Acquisition of Turkish”. In: Slobin, D.I. (ed.). The crosslinguistic study of language acquisition. London: Lawrence Erlbaum. 839878.

Altınkamış, F., S. Kern and H. Sofu. 2014. "When context matters more than language: Verb or noun in French and Turkish caregiver speech". First Language 34(6). 537 550 .

Bates, E.V., D. Marchman, L. Thal, L. Fenson, P. Dale, S. Reznick, J. Reilly and J. Hartung. 1994. "Developmental and stylistic variation in the composition of early vocabulary". Journal of Child Language 21. 85-123.

Bornstein, M. H., L.R. Cote, S. Maital, K. Painter, S. Park, L. Pascual, M.G. Pêcheux, J. Ruel, P. Venuti and A. Vyt. 2004. "Cross-linguistic analysis of vocabulary in young 
children: Spanish, Dutch, French, Hebrew, Italian, Korean, and American English". Child Development 75. 1115-1139.

Caselli, C., P. Casadio and E. Bates. 1999. "A comparison of the transition from first words to grammar in English and Italian". Journal of Child Language 26. 69-111.

Choi, S. and A. Gopnik. 1993. "Nouns are not always learned before verbs: An early verb explosion in Korean". Paper presented at the 25th Child Language Research Forum, Stanford University.

Choi, S. and A. Gopnik. 1995. "Early acquisition of verbs in Korean: A cross-linguistic study". Jouurnal of Child Language 22. 497-529.

Conboy, B. T. and D.J. Thal. 2006. "Ties between the lexicon and grammar". Child Development $77.712-735$.

De Houwer, A. 1995. "Bilingual language acquisition”. In: Fletcher, P. and B. MacWhinney (eds.), The handbook of child language. Cambridge, MA: Blackwell Publishers. 219-205.

Field, A. 2009. Discovering statistics using SPSS. London: Sage.

De Houwer, A., M.H. Bornstein and D.L. Putnick. 2014. "A bilingual-monolingual comparison of young children's vocabulary size: Evidence from comprehension and production". Applied Psycholinguistics 35(6). 1189-1211.

Gentner, D. 1981. "Some interesting differences between verbs and nouns". Cognition and Brain Theory 4. 161-178.

Gentner, D. 1982. "Why nouns are learned before verbs: Linguistic relativity versus natural partitioning”. In: Kuczaj, S. (ed.), Language development. (Vol. 2. Language, thought, and culture.) Hillsdale, NJ: Erlbaum. 301-333.

Gentner, D. and L. Boroditsky. 2009. "Early acquisition of nouns and verbs: Evidence from Navajo". In: Gathercole, V. (ed.), Routes to language: Studies in honor of Melissa Bowerman. New York, NY: Taylor \& Francis. 5-36.

Gillis, S. and A. Verlinden. 1988. Nouns and verbs in early lexical development: Effects of input frequency? Antwerp: University of Antwerp.

Jackson-Maldonado, D., D. Thal, V. Marchman, E. Bates and V. Guitierrez-Clellen. 1993. "Early lexical development of Spanish-speaking infants and toddlers". Journal of Child Language 20. 523-549.

Kambanaros, M. 2013. "Does verb type affect action naming in specific language impairment (SLI)? Evidence from instrumentality and name relation". Journal of Neurolinguistics 26(1). 160-177.

Kambanaros, M. 2016. "Verb and noun word retrial in bilingual aphasia: A case study of language- and modality-specific levels of breakdown". Journal of Bilingual Education and Bilingualism 19(2). 169-184.

Kambanaros, M., K.K. Grohmann, M. Michaelides and E.Theodorou. 2014. "On the nature of verb-noun dissociations in bilectal SLI: A Psycholinguistic perspective from Greek". Bilingualism: Language and Cognition 17(1). 169-188.

Kauschke, C. and C. Hofmeister. 2002. "Early lexical development in German: A study on vocabulary growth and vocabulary composition during the second and third year of life". Journal of Child Language 29. 735-757.

Kern, S. 2004. "Semantic distribution of French-speaking children's first words". In: Drevillon, J., J. Vivier, and A. Salinas. (eds), Proceedings of ISAPL 2000. Caen, France: Europia. 
Kern, S. 2007. "Lexicon development in French-speaking infants". First Language 27. 227-250.

Kern, S. and F.A. Türkay. 2006. "Influence cognitive générale et ou langagiéré spécifique sur les premiers mots des enfants: Etude pilote chez des enfants français et des enfants turcs". Poster presentend at ARCo. Colloque de l'Association pour la Recherche Cognitive. France: Bordeaux.

Ketrez, N. and A. Aksu-Koç. 2003. "Acquisition of noun and verb categories in Turkish”. In: Özsoy, A.S., D. Akar, M. Nakipoğlu-Demiralp, E. Erguvanlı Taylan and A. Aksu-Koç (eds.), Proceedings of the tenth international conference in Turkish linguistics. Istanbul: Boğaziçi University Press. 239-245.

Küntay, A. and D.I. Slobin. 2001. "Discourse behavior of lexical categories in Turkish child-directed speech: Nouns vs. verbs". In: Almgren, M., A. Barreña, M. Ezeizabarrena, I. Idiazabal and B. MacWhinney. (eds.), Research on child language acquisition: Proceedings for the 8th conference of the international association for the study of child language. Cascadilla Press. 928-946.

Lucas, I.G. and A.B.I. Bernardo. 2008. "Exploring noun bias in Filipino-English bilingual children". The Journal of Genetic Psychology: Research and Theory in Human Development 169(2). 149-164.

Marchman, V., C. Martinez-Sussman. 2002. "Concurrent validity of caregiver/parent report measures of language for children who are learning both English and Spanish". Journal of Speech, Language and Hearing Research 45. 983-997.

Ogura, T., P.S. Dale, Y. Yamashita, T. Murase and A. Mahieu,. 2006. “The use of nouns and verbs by Japanese children and their caregivers in book-reading and toy-playing context". Journal of Child Language 33. 1-29.

Tardif, T. 1993. Adult-to-child speech and language acquisition in Mandarin Chinese. (PhD dissertation, Yale University, New Haven.)

Tardif, T. 1996. "Nouns are not always learned before verbs: Evidence from Mandarin speakers' early vocabularies". Developmental Psychology 32. 492-504.

Tardif, T., M. Shatz. and L. Naigles. 1997. "Caregiver speech and children's use of nouns versus verbs: A comparison of English, Italian and Mandarin”. Journal of Child Language 24. 535-565.

Taxitari, L., M. Kambanaros, and K.K. Grohmann, 2016. "Investigating early language development in a bilectal context”. In: Babatsouli, E. and D. Ingram (eds.), Proceedings of the international symposium on monolingual and bilingual speech. 384-395.

Trask, R.L. 1999. "Parts of speech”. In: Brown, K. and J. Miller (eds.), Concise encyclopaedia of grammatical categories. Oxford: Elsevier. 278-284.

Türkay, F. 2005. Children's early lexicon in terms of noun/verb dominance. (PhD dissertation, Çukurova University, Adana.)

Xuan, L., and C. Dollaghan. 2012. "Language-specific noun bias: Evidence from bilingual children". Journal of Child Language 40(5). 1057-1075.

Zink, I. and M. Lejaegere. 2002. N-CDIs: Lijsten voor communicatieve ontwikkeling. Aanpassing en hernormering van de MacArthur CDIs van Fenson et al. Acco, Leuven (Belgium)/Leusden (Netherlands). 


\section{APPENDIX 1}

Lexical categories and gestures in the T-CDI-I and in the N-CDI-I.

\begin{tabular}{|c|c|c|c|}
\hline \multicolumn{2}{|c|}{ 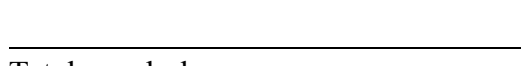 } & \multirow{3}{*}{$\frac{\text { N-CDI }}{434}$} & \multirow{3}{*}{$\frac{\mathrm{T}-\mathrm{CD}}{418}$} \\
\hline Tot: & vocabulary & & \\
\hline & Items in the categories & & \\
\hline 1. & Sound effects \& animal sounds & 17 & 10 \\
\hline 2. & Vehicles & 12 & 7 \\
\hline 3. & Toys & 11 & 8 \\
\hline 4. & Animal names & 38 & 17 \\
\hline 5. & Food and drinks & 41 & 43 \\
\hline 6. & Clothing & 21 & 18 \\
\hline 7. & Words about time & 7 & 6 \\
\hline 8. & Body parts & 21 & 17 \\
\hline 10. & Games and routines & 17 & 31 \\
\hline 11. & Question words & 4 & 7 \\
\hline 12. & Quantifiers and articles & 6 & 8 \\
\hline 13. & Pronouns & 10 & 12 \\
\hline 14. & Small household items & 36 & 27 \\
\hline 15 . & Descriptive words & 35 & 25 \\
\hline 16. & Action words & 57 & 95 \\
\hline 17. & Outside things \& places to go & 35 & $21+13$ \\
\hline 18. & People & 19 & 21 \\
\hline 19. & Prepositions \& localizations & 14 & 10 \\
\hline
\end{tabular}

\section{APPENDIX 2}

Lexical categories in the T-CDI-II and in the N-CDI-II.

\begin{tabular}{llll}
\hline & N-CDI & T-CDI \\
\hline & Total vocabulary & 702 & 711 \\
$\quad$ Items in the categories & & \\
1. Sound effects \& animal sounds & 21 & 13 \\
2. $\quad$ Vehicles & 17 & 14
\end{tabular}


3. Toys $19 \quad 20$

4. Animal names $\quad 47 \quad 41$

5. Food and drinks $69 \quad 66$

6. Clothing $29 \quad 32$

7. Words about time $15 \quad 13$

8. Body parts $31 \quad 37$

9. Furniture and rooms $\quad 34 \quad 27$

10. Games and routines $\quad 26 \quad 40$

11. Question words $7 \quad 72$

12. Quantifiers and articles $\quad 16 \quad 23$

13. Pronouns $23 \quad 21$

14. Small household items $\quad 52 \quad 33$

15. Descriptive words $\quad 60 \quad 61$

16. Action words $106 \quad 146$

17. Outside things $28 \quad 37$

18. Places to go $23 \quad 25$

19. People $29 \quad 32$

20. Prepositions \& localizations $\quad 25 \quad 21$

21. Auxiliaries 19

22. Conjunctions $\quad 6 \quad 7$

\section{Address correspondence to:}

Fatma Hülya Özcan

Department of English Language Teaching

Anadolu University

Yunus Emre Kampusu

Eskișehir, 26470

Turkey

fozcan@anadolu.edu.tr 